\title{
Fair Disclosure of Inside Information by Listed Companies: A comparative study between the UK and Kuwait
}

\author{
Abdullah R.A.S. Al-Sheblia \\ ${ }^{a}$ Assistant Professor, Saad Al-Abdullah Academy for Security Sciences (Private Law Department), Kuwait, ugulf@live.com
}

Received: 8 November 2018, revised: 7 February 2019, accepted:26 March 2019, published:9 April 2019

\begin{abstract}
In Kuwait, the Capital Markets Act 2010 (the Act) gives the regulatory authority the power to pass disclosure rules. However, the Act does not mention how to improve such disclosure rules. Therefore, this article will discuss the concept of protecting individual investors, which involves ensuring fair disclosure by listed companies, because informed investors are protected investors. This article will discuss the idea of having fair disclosure to protect investors, to ensure that all investors have an equal opportunity to know about inside information in an appropriate and timely manner. This article will also examine the existing disclosure rules that apply to equity shares in Kuwait as compared to the UK's disclosure regime as examples of developed countries.
\end{abstract}

Keywords: Disclosure rules, Inside information, Kuwait securities market

JEL codes: K22, G28, P12, G34, M38, M31.

\section{INTRODUCTION}

Inside information is specific information related to a company that, if published, would be likely to have a significant effect on its share prices. It is a piece of key information that makes individual investors aware of fundamental benefits and risks when making an investment decision (buying, selling or deferring investment). Disclosure of inside information should be accurate, honest, understandable, full, timely and not misleading. Fair disclosure is one way to protect investors by ensuring that all investors have an equal opportunity to access and be aware of inside information at an appropriate time and in an appropriate way. Some say that "informed investors are protected investors" (Burke, 2009).

The disclosure of inside information by listed companies is one of the most important objectives of the Kuwait securities market. For instance, the Kuwaiti legislation stresses the importance of disclosure of information in accordance with the provision of Article 3 of Kuwaiti Law No 7 of 2010, which states that one of the Kuwaiti Capital Market Authority's objectives is "implementation of a policy of full disclosure in order to achieve justice, transparency and prevent conflicts of interest and the exploitation of inside information".

The question here is how to enhance the information disclosure regime and avoid the lack of access to information in order to protect investors. Without doubt, disclosure of inside information plays a significant role in protecting investors, because they rely on this information to make their investment decisions. Information disclosure is a key element in the protection of investors (Burke, 2009).

Several forms of disclosure are required from equity share companies, such as notification of transactions by persons discharging managerial responsibilities (disclosure of dealing), periodic reporting (annual and halfyearly reports), notification of the acquisition or disposal of major shareholdings, including, for example, acquisition or disposal by issuers and, finally, disclosure of inside information. For example, in the UK, in 2011 Morrison's supermarket retired chairman Sir Ken Morrison was fined $£ 210,00$ by the Financial Services Authority (FSA) for violating disclosure and transparency rules by reducing his shareholding and voting rights without disclosure (FSA, 2011).

This article concentrates on inside information, because it plays a significant role in the market and is related to investor protection. Moreover, it can be taken as an example of how to control the other types of disclosure. Importantly, in some situations, other disclosures have the potential to be considered inside information, such https://doi.org/10.30585/jrems.v111.317

(C) 2019 the Authors. Production and hosting by Avicenna FZ LLC. on behalf of Dubai Business School, University of Dubai - United Arab Emirates. This is an open access article under the CC BY-NC license. 
as early profit warnings. In addition to financial information, there is non-financial information such as changing of members of the board and key executives. The question is how to enhance the disclosure regime to be able to prevent a future problem in equities markets and attempt to control the regime, by highlighting some shortcomings in the recent rules or closing existing loopholes, so that listed companies cannot abuse the rules by breaching information disclosure regulations or avoid them by using a legal loophole.

This article examines the existing disclosure rules which apply to equity shares in Kuwait compared to the UK's disclosure regime as examples of developed countries.

\section{THE REGULATORY FRAMEWORK FOR DISCLOSURE}

Inside information is governed by several rules, which often overlap. The first set of rules consists of the Listing Rules, which impose a continuing obligation in respect of listing of equity shares for listed companies to disclose meaningful information. The second set of rules comprises the Disclosure Rules. For example, the UK and Kuwait have specific rules for disclosure. The third set is the Market Abuse Rules and the fourth set comprises the criminal offences associated with disclosure. Some describe the first two as positive obligations of disclosure and the last two as negative obligations relating to disclosure (McDonnell, 2012). These rules have the potential to provide better protection for investors by ensuring that the market operates on the basis of equal access and fair disclosure of inside information and by ensuring that the disclosure does not mislead investors' decisions.

These rules overlap in certain circumstances; for instance, according to the listing rules in the UK, which also includes listing principles (LR 9.2.5G), a listed company must comply with the Disclosure and Transparency Rules (DTRs). In addition, there is an overlap with the Financial Services and Markets Act $2000 \mathrm{~s} 118$ (market abuse) and s397 (misleading statements and practices) that will be discussed later. An overlap also exists between the listing rules and the disclosure rules with regard to punishment. This overlap may be seen in the enforcement decision of the FSA (now FCA) in the UK against Woolworths Group plc for disclosure rule and listing principle breaches which saw the company fined $£ 350,000$ in 2008 (FSA, 2008).

The following section considers regulation in the UK and Kuwait.

\subsection{United Kingdom}

Before 2005, the disclosure obligations were part of the listing rules, which are known as Admission of Securities to Quotation or Admission of Securities to Listing. In 2005, the Disclosure Rules were introduced to implement the Market Abuse Directive (MAD). During that same year, in the UK, the FSA (now FCA) extended the listing regime by adding Listing Principles (11 principles) to implement the MAD. The Financial Services Authority believed that these principles would support the requirements of European law (McDonnell, 2012, p. 16). For example, Listing Principle 2 establishes procedures, systems and controls for disclosing information and is one of the positive obligations imposed on an issuer to comply with the rules of the UK Listing Authority (UKLA).

In 2007, to implement the Transparency Directive new rules were added to the Disclosure Rules, which then became the Disclosure and Transparency Rules (DTR). Moreover, in 2008, DTRs 1B and 7 (Corporate Governance Code) were added to implement parts of the Statutory Audit Directive and the Company Reporting Directive (McDonnell, 2012, p. 19). (In this article, DTR is the abbreviation for the Disclosure and Transparency Rules.)

The MAD applies to all issuers of securities that are admitted to trading on a regulated market (Wolfson, 2012, p. 224). Therefore, this section regarding the UK regime is limited to consideration of the premium listing of equity shares.

Listing Principle 11 mentioned above states, "A firm must deal with its regulators in an open and co-operative way, and must disclose to the FSA appropriately anything relating to the firm of which the FSA would reasonably expect notice". The text states that firms have to disclose to the FSA (now FCA) all relevant information pertaining to a disclosure. However, it does not set out the procedure for the said disclosure, leaving it to the judiciary to interpret the law. This is a good example of the judicial system applying the law. The particular law will set out general terms and principles whereas the courts will handle the application of the law and provide details in their judgments.

The enforcement cases play a significant role in the inside information system. Since April 2013 the Financial Services Authority (FSA) has been replaced by the Financial Conduct Authority (FCA). The Financial Conduct Authority (FCA) enforcement procedure for disciplinary cases is as follows:

1) Appointment of Investigators. 
2) Initial discussions with the firm or individual that are intended to provide a clear indication of the scope of the investigation.

3) The appointed investigators carry out the investigation.

4) If appropriate, the investigators send a Preliminary Investigation Report (PIR) to the firm or individual, who has 28 days to respond.

5) The parties can seek to resolve the issue by having settlement discussions with FCA at any stage in the procedure.

6) If, following their investigation, FCA staff believe action is justified they submit case papers to the Regulatory Decisions Committee (RDC).

7) If the RDC decides it is appropriate, it will send out a Warning Notice informing the person concerned that the FCA intends to take further action.

8) The RDC will then meet again to consider the facts of the case, including the firm's or individual's written representation and any new information that may have come to light.

9) The RDC makes its decision and, if appropriate, issues a Decision Notice. The firm or individual has 28 days to make a referral to the Upper Tribunal (Tax and Chancery Chamber).

An example of this procedure in action was the enforcement decision made by the FSA against Prudential in 2010. The company was fined as a result of its failure to inform the FSA in a timely manner that it was seeking to acquire AIA, the Asian subsidiary of AIG. The failure to inform the FSA was important. As Prudential did not inform the FSA of the proposed acquisition until after it had been leaked to the media on 27 February 2010, the FSA considered that the circumstances of these breaches was serious, and therefore fined the firm.

\subsection{Kuwait}

In some Gulf Cooperation Council (GCC) countries, there is no distinction between disclosure rules and listing rules. Listing rules comprise rules about how to access the market as well as rules about the disclosure of information. Kuwait relies on listing rules as well as disclosure rules to control the disclosure of information, similar to the UK.

The basic statutory framework for disclosure of securities in Kuwait is set by the Capital Market Authority in two rules, Rule No 3 of 2011, relating to listing, and Rule No 2 of 2012, relating to disclosure.

\section{WHAT IS DISCLOSURE OF INSIDE INFORMATION?}

This article illustrates some examples of inside information and the extent to which the definition varies from country to country. For example, Kuwaiti legislation provides approximately 25 examples of inside information, after which it gives a general standard for determining inside information.

For the purposes of this article, disclosure of inside information means full, timely and accurate disclosure of information about a listed company's activities to provide equal opportunities of investment and to promote investor confidence and market integrity. Therefore, issuers are required to provide investors with information that could affect their investment decisions, because such information can affect the prices of securities. According to Article 1 of the Kuwaiti Disclosure Rules 2/2012, the issuer means a legal person (legal entity) whose security has been listed on a stock market. The FSA (now FCA) Director of Enforcement and Financial Crime, Tracey McDermott, stated: "The integrity of our markets depends on listed companies making timely and accurate disclosures ..." (FSA, 2013). Examples of inside information that must be disclosed are material events, major changes in company policies and decisions related to a major investment or capital purchase.

Ensuring that investors are sufficiently informed is one of the reasons for the regulatory intervention in financial markets that could help an investor to make a suitable investment assessment. In an enforcement decision taken by the FSA against JJB Sports PLC, which was fined $£ 455,000$ for failing to disclose information to the market, the FSA (now FCA) Director of the Markets, Alexander Justham, stated: "JJB's failure to disclose information ... denied investors the ability to fully understand its financial position and make informed investment decisions" (FSA, 2011). If the market fails to protect investors from making bad decisions because of inadequate or incomplete information, and if, as a result, investors lose confidence in the market, investors will withdraw from the market forever, and the market will suffer from reduced liquidity (McDonnell, 2012, p. 3).

There is a difference between immediate disclosure and periodic disclosure. The former requires that information and events that may affect the securities' prices must be disclosed without delay to the market. The latter requires that the listing companies prepare and publish financial periodic reports (quarterly, semi-annual and annual reports). 


\section{CONTROL OF DISCLOSURE}

Several obligations are related to disclosure during the listing period, such as the disclosure of inside information. However, disclosing the information in time to allow all investors acquire the knowledge is one of the most important goals of disclosure rules. Therefore, the questions here are: how to define the inside information and what is a suitable time for disclosure?

It is a difficult challenge to identify material (inside) information and to determine the appropriate time to announce it. For example, in Kuwait, a seminar organised by the Kuwaiti Capital Markets Authority (KCMA) related to the disclosure of inside information was attended by a large number of legal advisers of listed companies and compliance managers from the Authority. A number of seminar participants expressed dissatisfaction with the many grey areas in the answers given by the Authority officials present. The KCMA officials stressed the need for the immediate disclosure of inside information. This was the subject of controversy when the audience asked about one of the criteria that determined what information is material. The Authority replied that this is determined by the issuers. Every piece of information that has an impact on the financial position is essential.

Commission officials stressed that any information that can lead to a change in the share price and trading volumes requires disclosure, even if it is secret or if the company is in the process of completing some of the agreements; for example, if a company has signed a confidentiality agreement to restructure or carry out a study with any of the consulting houses. The officials emphasised the need to disclose to the Commission and the Stock Exchange before publishing the announcement in the newspapers and the media in general or on the company's website. One member of the audience complained that the Authority laid down harsh sanctions despite having failed to set accurate and clear standards to identify inside information. Another attendee expressed dismay that the disclosure requirements may reveal important information about pricing and secrets to competitors, which may prove unfair to listed companies as most of their competitors are not listed in the Stock Exchange. This discussion reveals a number of criticisms of the system of disclosure. In addition, in practice, there is difficulty in identifying inside information because of the lack of an accurate standard and because issuers can differ in their understanding of fundamental information.

In Kuwait, prior to 2012, the situation was addressed only under the Listing Rules. In particular, Article 13 states that members of the board of directors of the company must provide all of the information and data required by the Authority. The Stock Exchange and either the Authority or the Stock Exchange can select the inside information, the nature of the information and the time of disclosure, which can lead to an unclear definition of material information. However, in 2012, the Kuwaiti legislature passed new disclosure rules 2/2012 designed to resolve these problems.

In the UK, the disclosure should be made as soon as possible, and there should be legitimate reasons for any delay. Therefore, it is unacceptable to delay the announcement because of a delay in obtaining approval from the board, because the company is preparing the announcement or because the presentation to analysts is not ready. However, this advice is contained in an FSA technical note on the disclosure and transparency rules, which is not binding and serves as an explanation. A timely disclosure is very important even though a listed company feels that delaying the disclosure will reduce its impact. This can be clearly seen from the FSA (now FCA) enforcement decision in 2009 against Entertainment Rights plc, which was fined $£ 245,000$ for failing to disclose inside information in a timely manner with a 78-day delay. Entertainment Rights plc entered into an agreement in the US in 2006 to distribute DVDs in the US. In July 2008, a variation to the agreement reduced the company's profits by US $\$ 13.8$ million. This variation was inside information. Inside information must be disclosed as soon as possible. Thinking that it had a chance to reduce the effects of this inside information in the future, the company delayed the announcement until 26 September, as a result its shares declined by 55 percent that day (FSA, 2009).

Assessing what constitutes inside information is not straightforward, because it depends on different factors, such as changes in the issuer's business, operations and capital. The issuer is best placed to determine whether inside information exists that could significantly affect securities' prices. Therefore, the best solution for controlling the disclosure of inside information is to make an issuer responsible for disclosure in a way that can be clearly seen from the listing principle in the UK, which mentions that adequate procedures, systems and controls must be established by an issuer (Listing Principle 2) to comply with its obligations.

\section{DELAY AND EXTENT OF DISCLOSURE}

The next section discusses delay in full disclosure, limited disclosure, initial and final disclosure and exemption from disclosure. 


\subsection{Delay in Full Disclosure}

In the UK, companies are allowed to delay their public disclosure of inside information if a number of conditions are met in certain circumstances according to DTR 2.5. Disclosure may be delayed if there is a legitimate interest, it is not misleading to the public, a duty of confidentiality is owed to the issuer by whomever is receiving the inside information and confidentiality is ensured by the issuer. Under no circumstances may the delay be based upon negative news, such as a financial difficulty. However, DTR 2.5.5AR allows a delay due to negative news if it is related to liquidity support from the Bank of England or another central bank (Wolfson, 2012, p. 240). Therefore, either negative or positive news must be made public as soon as possible. This point was supported by the Managing Director of the Wholesale and Institutional Market at the FSA (now FCA), who said in the case of concerning Wolfson Microelectronics plc, "it is unacceptable for a company not to disclose negative news, because it believes other matters are likely to offset it. Doing this hampers an investor's ability to make informed investment decisions and risks distorting the market value of a company's shares" (FSA, 2009).

An example of positive and negative disclosure can be found in the FSA enforcement decision in June 2010, when Photo Me International plc was fined $£ 500,000$ for disclosing inside information 44 days late. In late 2006, Photo Me announced positive news about winning large sales contracts, as the result of which its share prices jumped. However, in January 2007, Photo Me learned that at least five other competitors were engaged in contract negotiations. This was inside information that Photo Me was obliged to disclose as soon as possible. In addition, in February 2007 Photo Me failed to reach its announced sales targets of 1,100 minilabs from 2006 to 2007 , and forecasts were revised down by 40 percent. Thus, it expected to sell 750 fewer minilabs during that period. This was also inside information that Photo Me was obliged to disclose as soon as possible. The inside information was closely monitored until the scheduled quarterly board meeting on 1 March 2007, when this was discussed. The next day, the price of its shares decreased by 24 percent (FSA, 2010).

In Kuwait, if inside information is delayed due to ongoing negotiations that have not yet been resolved, or if there are contracts or agreements requiring accreditation from another party to become effective, an issuer has the right to request a delay of disclosure from the KCMA, if there is no possibility of misleading the public and there is a guarantee from the issuer that the inside information will remain confidential, according to the Kuwaiti Disclosure Rules 2012, Article 5.

\subsection{Limited Disclosure}

Kuwait and the UK have a provision for limited disclosure in certain circumstances. Article 7 of the Kuwait Rules 2/2012 mentions that limited disclosure, referred to as selective disclosure, is allowed in some circumstances for certain persons. However, it does not mention any other conditions, such as requiring selected persons to pledge to keep inside information confidential and banning dealing on the basis of this information until it is made public. In the UK, companies are allowed to disclose inside information to a person who owes a confidential duty to the issuer provided that other conditions are also met. However, it is unacceptable to disclose inside information to journalists, for example, because they do not have a duty of confidentiality to the issuer (FSA technical note, p. 8).

\subsection{Initial and Final Disclosure}

If a serious and unexpected event occurs, and the company needs more time to understand the situation before making a disclosure, it can apply to the regulatory authorities for a temporary halt in trading or make an initial disclosure to be followed later by a full disclosure. Kuwaiti rules all allow for a temporary halt in trading. Sometimes, a serious and unexpected event can happen, the company needs more time before disclosing the situation, and there is a risk that inside information will leak out before disclosure occurs. Under these circumstances, the company may make an initial disclosure giving enough relevant details, explaining why it cannot publish all of the details and pledging to disclose more details as soon as possible. In addition, the company must request that the trading of its shares stop if it is unable to publish the announcement or if it declines to publish it. Furthermore, according to Article 4, part 3 of the Kuwaiti Disclosure Rules, if something unexpected, sudden or significant happens, an issuer may request an interim cessation of dealing if the issuer wishes to delay the disclosure for a short period.

\subsection{Exemption from Disclosure}

Some legislation exempts a company from disclosure in certain circumstances. Exemption from disclosure of information provides that the Capital Market Authority may accept non-disclosure of some information, such as when this kind of information would not damage or affect the investor's ability to assess the cost, benefits and investment risk. Other examples are when the disclosure is likely to affect the issuer's interest and when the public interest is expected to be affected by the disclosure. In addition, there are obligations after approval of 
the non-disclosure of information. First, the issuer must control the information and limit its scope as much as possible. Second, any person who might have knowledge of this information shall not use it or disclose it to another person without written acknowledgment from that person that he will not use the information for personal interest and will not disclose it to others. Third, the issuer must monitor the trading of any person who may know about this information and trading by their relatives or others with whom the person has a close personal, commercial or financial relationship.

It is a vague and strange text, because if information does not affect the prices of shares and is therefore not inside information, why is there an exemption? In addition, it is illogical to prevent disclosure because of negative news, because positive and negative news must be disclosed.

\section{DEALING WITH RUMOURS}

Companies should do their utmost to prevent any leak of information which may give rise to rumours. The greater the delay in disclosure of the correct information the higher the risk of rumours. The disclosure rules also deal with rumours and false information which may arise as a result of a delay in disclosing the correct information. For example, in the foregoing circumstances, the UKLA may ask the issuer to disclose inside information or to establish the truth. Otherwise, under DTR 1.3.3, the UKLA can use its powers to require the issuer to publish inside information to protect investors or to ensure the smooth operation of the market. The UKLA can also suspend an issuer's securities from trading if the issuer refuses to disclose inside information. On the other hand, under DTR 2.7 the issuer has an obligation to take appropriate action if there is press speculation and market rumours. This means that the issuer has to judge whether it needs to make a disclosure under DTR 2.2.1. The question here is whether such disclosure to make an announcement needs to be in a formal manner. The UKLA does not usually require such an official announcement. However, in practice, if the announcement has the potential to affect the issuer's share price it would be better to make a formal announcement (FSA technical note, pp. 1, 2, 9).

In Kuwait, under the Kuwait Disclosure Rules 2/2012 Article 6 an issuer should immediately clarify, confirm or deny, without any delay, when there is speculation, news or current information related to the issuer's shares that is likely to affect the price of its securities or is linked to the investment decisions of traders, regardless of whether the information is true or false. Here, if the unusual trading does not stop, the Kuwait Authority has the right to impose a temporary suspension of trading.

Sometimes, some people may take advantage of a rumour that is the result of the lack of clear disclosure or of leaks. This can cause unusual trading activity. For example, in Kuwait, if unusual trading occurs the issuer must take one of the following actions:

1) Re-disclose inside information if the issuer determines that it happened as a result of a previous disclosure.

2) Consult with the Authority if an issuer believes that it happened as a result of the absence of interpretation or a misunderstanding.

3) Comment immediately without delay if there are rumours.

4) Disclose inside information if there are leaks of information.

5) Make a general announcement, including that nothing new has happened, if the issuer does not find the reason for the unusual trading.

Therefore, under the Kuwait Disclosure Rules 2/2012 Article 6 the Authority could apply a temporary suspension if the issuer could not resolve the unusual trading.

\section{IMPROVING THE DISCLOSURE REGIME}

Disclosure should empower investors and give them the opportunity to make an informed decision. It is not enough simply to draft disclosure rules. There also has to be a suitable mechanism for implementing them (Moloney, 2010). This is lacking in Kuwait in varying degrees. In the UK, several mechanisms exist, namely, the listing principle, director responsibilities, the insider list, the reasonable investor standard, the adviser and holiday disclosures.

\subsection{Listing Principles}

In the UK, all listed companies with a premium listing of equity shares are subject to the Listing Principles. The main objective of the listing principles is to aid listed companies to identify their duties under DTR and Listing Rules (Wolfson, 2012, p. 284). The disclosure rules in Kuwait do not mention these principles. Listing principles are a part of the listing rules, and if they are breached, the FCA can apply disciplinary action against the listed 
company. However, investors cannot take any action against a listed company when it breaches the listing principles (Wolfson, 2012, p. 284).

The three most important listing principles are Principles 1, 2 and 4.

1) Listing Principle 1 relates to 'reasonable steps' to make the directors of the issuer aware of their responsibilities and obligations. For instance, receiving suitable continuing training to understand any change or update of listing rules or DTRs is one way to achieve the goal of Principle 1 (Wolfson, 2012, p. 285).

2) Listing Principle 2 sets out adequate procedures, systems and controls to be taken by an issuer in order to fulfil its obligations in an appropriate way. The two most important points are when such an obligation arises and how to achieve a timely and accurate disclosure. Directors must take reasonable steps to control the flow of information in addition to assessing its significance according to Listing Principle 2.

3) Listing Principle 4 covers avoiding establishing false market information by communicating to holders and potential holders of shares.

Recently, the FCA has placed more emphasis on the application of these principles. In 2013, the FCA fined Lamprell plc $£ 2,428,000$ for systems and controls failings. The company breached Principle 2, because it was unable to adequately monitor its financial performance, and it could not keep the market completely informed of its deteriorating financial position (FCA, 2013).

\subsection{Directors' Responsibilities}

There are two important points concerning how to control inside information. The first is how to determine that the information is inside information. The second is how to establish a suitable time for the disclosure. Making a limited group from the board of directors responsible for releasing inside information to the public could improve the situation and could make it highly susceptible to control.

In the UK, this responsibility is frequently delegated by the issuer's board of directors to a small group of directors, because they can act quickly. Principle 1 of the Listing Rules in the UK was created to make the directors responsible for the disclosure aware of their obligations (Principle 1). Thus, the rest of the board should not communicate with the press, analysts or investors or talk about information if they are not aware of the issuer's policy regarding inside information and they are not authorised to be responsible for identifying, controlling and disseminating inside information. This is a serious problem, which the issuer should face. The FSA (now FCA) confirmed this by saying:

In our experience, a number of problems and uncertainties that issuers have faced in handling inside information have arisen because they have not identified ... those employees who are responsible for communication ... staff should be prohibited from communicating information to outside the issuer if they have not been given this responsibility (FSA technical note, p. 3).

In practice, this point could also help the staff to avoid being under pressure to disclose confidential information. Also, in the UK, Listing Rule 9.2.11R mentions 'the contact person', which means at least one suitable person with knowledge about the company who maintains contact with the FCA and whom the issuer must nominate as the first point of contact regarding listing rules and DTRs.

In Kuwait, the general requirement in the applications for listing is that the company's board members must pledge to adhere to all of the rules and regulations set by the Stock Exchange and to provide the Authority and the Stock Exchange with all of the required data and information, provided that the information is correct and reliable according to Article 13 of Decision No 3 of the Kuwaiti Disclosure Rules 2012. Article 3 of these rules states that the issuer is responsible for the disclosure and for selecting the appropriate time for the disclosure. In practice, it would be better if the responsibility for both disclosing and deciding a suitable time for the disclosure were limited to a small group of the issuer's directors, who have ongoing training and are aware of updated disclosure rules.

\subsection{Insiders' Lists}

In the UK, the issuer has to provide the FCA with an insider list detailing the persons who have access to inside information (DTR 2.8). The issuer must keep this list ready and when the FCA requests it, the issuer must provide this list as soon as possible. In the UK, 'as soon as possible' means without delay (Blair, Walker \& Willey, 2012, p. 198).

Any person working for the issuer with access to inside information directly or indirectly and anyone acting on behalf of the issuer is an insider and must be listed. The issuer must keep the list for at least five years (DTR 
2.8.5R) and it must include the identity of each person, why he or she is on the list and the date on which the insider list is updated (DTR2.8.3R). The list must be immediately updated with any change about the insiders (DTR 2.8.2R). This list should also include how the person became an insider, in order to monitor and regulate the person's activities, because it is difficult to ensure that insiders and investors have equality of information at the same time.

In theory, some people have access to inside information, but should not be included in the insider list. For example, the issuer may employ an adviser to help determine whether information has reached the level of inside information, or to provide assistance if an issuer does not know how to apply the Disclosure and Transparency Rules or Listing Rules. The adviser may employ someone to do photocopying. This person should not be included in the list of insiders (FSA technical note, p. 10).

Kuwaiti legislation, too, should consider adding such a requirement to its disclosure regime to oblige issuers to prepare a list of insiders.

\subsection{An Adviser}

In the UK, an issuer can use an appropriate adviser to consult about any information, especially to know whether the information reaches the level of inside information. The FCA does not specify a particular type of adviser, and companies cannot rely on the adviser's opinion to determine whether information needs to be disclosed. This can be clearly seen from the enforcement decision regarding Wolfson Microelectronics plc (Wolfson) in which the FSA (now FCA) fined the company $£ 140,000$ for delaying the disclosure of inside information for 16 days, although its adviser had erroneously advised that negative news did not have to be disclosed. The Managing Director of Wholesale and Institutional Markets at the FSA (now FCA), Sally Dewar, supported this point, saying that, "companies have the primary responsibility for meeting their disclosure obligation ... they cannot rely ... on such advice" (FSA, 2009).

Kuwait's rules make no mention of how to use an appropriate adviser to consult about any information.

\subsection{The Reasonable Investor Standard}

According to DTR 2.2.4G(1), an issuer must take into account the reasonable investor standard when determining whether the information is price sensitive. In other words, whether the investment decision of a reasonable investor would be significantly affected by undisclosed information if it were made public knowledge. In the 2011 case of David Massey v FSA, it can be seen that the Upper Tribunal took the reasonable investor test into account when it upheld an enforcement decision made by the FSA (now FCA) to impose a penalty of $£ 150,000$ against Mr. Massey. Mr. Massey used short selling in Eicom Plc shares and made a net profit of $£ 100,000$ in the UK Alternative Investment Market (AIM), based on insider information that the issue of discount shares was available to him. The Upper Tribunal believed that this kind of information would influence a reasonable investor by saying that, "Information would be likely to have a significant effect on price if and only if it is information of a kind which a reasonable investor would be likely to use as part of the basis of his investment decision". This evaluation is broadly different from one issuer to another, because in fact it depends on different factors, such as the sector, the issuer's activities, and the reliability of the sources of information (Wolfson, 2012, p. 228).

The Kuwaiti Disclosure Rules 2/2012 have taken a prudent person standard to determine inside information. The standard is defined as a person who seeks to maximise his benefits if he can use the inside information when making his investment decisions. Disclosure rules emphasise that a prudent person standard varies from one investor to another depending on several factors, such as the issuer's size, recent developments, the general situation of the market and, in particular, the issuer's sector.

\subsection{Weekend Disclosure}

In the UK, there is what is known as the 'Friday Night Drop' case. The name comes from the fact that when a Regulatory Information Service (RIS) is closed on Friday evening, the permitted delay in disclosure to the authorities is until the RISs reopen on Monday morning. However, over the weekend the information must be made public by the company in one newspaper. Regulatory Information Services (RISs) are the places that must disseminate inside information on behalf of listed companies after receiving the full text of the regulatory disclosure, and after the disclosure has been approved by the FSA. This situation is not clear in Kuwait.

Article 4 of the Kuwaiti Disclosure Rules states when the disclosure should take place. It provides that the disclosure should occur immediately, without delay during the trading time or before a dealing session. However, unlike the UK, there is no provision for holiday time. 


\subsection{Form of the Disclosure}

The Kuwaiti Disclosure Rules do not require a written form of disclosure; any means available is allowed. A written announcement helps to explain the information and to provide clarity. Since Kuwaiti laws do not require a special method of disclosure, it would be better if they required a written form for the disclosure. In the UK, regulatory disclosure must be written (FSA technical note, p. 2).

\section{SANCTIONS FOR FAILURE TO DISCLOSURE}

Since laws must provide a regime to punish those who breach the information disclosure regime, the civil liability, the criminal liability and the administrative sanctions available must be considered.

\subsection{Administrative (civil) Fines}

In the UK, the FCA can impose administrative sanctions in the form of a fine, a public censure and/or other. Under s118 of the Financial Services and Markets Act 2000 (FSMA), the FCA can impose civil sanctions if the disclosure takes the form of market abuse. This regime also deals with misleading statements and practices. Section 118(c) defines inside information as follows. Unless the rules permit delay, an RIS must be notified by issuers about inside information as soon as possible if the information concerning the issuer is of a precise nature, has significant effect, and differs from issuer to issuer depending on different factors, such as recent developments and the issuer's size (Blair, Walker \& Willey, p. 197).

The Financial Services and Markets Act 2000 s118(d) states:

Information is precise if it (i) indicates circumstances that exist or may reasonably be expected to come into existence or an event that has occurred or may reasonably be expected to occur, and (ii) is specific enough to enable confusion to be drawn as to the possible effect of those circumstances or that event on the price of qualifying investment or related investments.

Furthermore, according to $s 118$ (d), "information would be likely to have a significant effect on price if it is information of the kind which a reasonable investor would be likely to use as part of the basis of his investment decisions".

In the UK, the FSA (now FCA) adopted a new policy in 2010 regarding the enforcement of financial penalties, as the result of which the number of fines increased. This was evidenced by the enormous size of the enforcement decision in 2013 against the Prudential Group, which was fined £30 million for breaching FSA (now FCA) principles and UKLA listing principles (FSA, 2013). The new policy is based on income. The penalty will be up to twenty percent of a firm's revenue from its business area and products. The penalty imposed on individuals who breach regulations in non-market abuse cases will be up to forty percent of the individual's benefits and salary. The penalty in cases involving serious market abuse by an individual is a minimum of $£ 100,000$ (FSA, 2010).

This policy seeks to achieve three objectives: disgorgement, deterrence and discipline. Its purpose is to change the behaviour of the market, as pointed out by Margaret Cole, FSA (now FCA) Director of Enforcement and Financial Crime, who stated that, "We believe enforcement penalties are a powerful tool to help change behaviour in the industry" (FSA, 2010).

In Kuwait, the KCMA can apply one of the administrative penalties included in Law No 72010 if the issuer does not comply with the Disclosure Rules 2012, under Article 12. However, administrative penalties do not include fines.

\subsection{Civil Liability}

The question here is how to compensate investors who suffer losses. The scope of civil responsibility includes any person who makes, or who is responsible for another person who makes, an untrue statement of material fact or omits material facts, whether orally or in written statements. He shall be liable for compensatory damages if the wrongdoing misleads another person in relation to buying or selling securities without the requirement of a relationship between the two parties. However, the claimant must prove first that he was not aware that the statement was untrue or omitted and, secondly, that he would not have sold or purchased if he had known about the information. Thirdly, the claimant must also prove that the person responsible for the disclosure knew about the untrue information included in the statement or was aware of the important material fact that was omitted. The third condition regarding the disclosure of false information seems to impose an unrealistic requirement that is almost impossible to accomplish, and it would be better if the burden of proof in this instance were on the Authority, because it has powers of investigation, or alternatively the issuer has to prove that he did not know that the information was untrue. 
In the UK, according to DTR1.3.4R, the issuers must take reasonable care to make certain that the disclosure is not misleading, false or deceptive and does not omit any information that could affect the importance of the disclosure information.

\subsection{Criminal Liability}

With regard to regulations about the disclosure of inside information required of listing companies, some companies could make such a disclosure wrongly by including false or misleading information or by omitting information.

In the UK, under s397 of the FSMA 2000, false disclosure can lead to a criminal offence when it creates a false impression in the market (misleading statements and conduct), which is punishable by up to seven years' imprisonment or an unlimited fine. In the 2005 case of $R v$ Rigby and Bailey, Bailey, who was the chief financial officer, and Rigby, who was the chief executive officer of AIT Group Plc, were convicted of misleading, false and deceptive conduct under FSMA s397. They were sentenced to nine months and eighteen months in prison, respectively.

In Kuwait, for criminal liability, Kuwaiti Law 2010 Article 120 imposes a fine of a minimum of 1,000 but not exceeding 100,000 KD, but no imprisonment, upon any person who has omitted, withheld or prevented material information for which the law required disclosure to the Authority or Stock Exchange regarding dealing or advising about selling or buying securities.

\section{CONCLUSION}

This article has dealt with the protection of investors from the perspective of the disclosure regime under Kuwait's Capital Markets Act 2010 and the FSMA Act 2000 in the UK and associated Listing and Disclosure Rules. To be protected, individual investors must have fair disclosure. Enhancing the disclosure regime mainly relies on rule-making, which is part of securities law. Disclosure is a positive action. Consequently, a firm that fails to disclose could face administrative sanctions even if the firm did nothing else wrong. There is an overlap between disclosure and listing rules. Listing rules are agreed by a listed company and a stock exchange.

International competition can affect the responsibility for regulating the stock exchange. This article has also examined the disclosure regime in Kuwait and compared it with the situation in the UK. In Kuwait, the 2010 Act does not empower the Kuwaiti regulatory authority to pass fines, which makes the disclosure regime less effective. In the UK, the FCA can pass unlimited fines.

It is difficult to assess what inside information needs to be disclosed, and when, in some cases, the disclosure of such information can legally be delayed, limited or exempted. In addition, there is a relationship between rumours and disclosure rules. All of these issues require regulatory rules. This article has found that a disclosure regime is a complicated subject, because many rules are related to disclosure; rules need to be updated over time, and some rules can affect stock market competition.

By comparing the situation in Kuwait with the situation in the UK, a number of recommendations have been made that could improve the effectiveness of the disclosure rules in Kuwait, such as having listing principles, increasing each director's responsibilities and preparing lists of insiders. Kuwaiti securities law should give the regulatory authority the power to impose fines, which could play a significant role in enforcing disclosure rules.

\section{REFERENCES}

\section{Legislation}

Financial Services Act 2012

Financial Services and Markets Act 2000

Directive 2006/46/EC of the European Parliament and of the Council of 14 June 2006 amending Council Directive 78/660/EEC in the annual accounts of certain types of companies, 83/349/EEC on consolidated accounts, 86/635/EEC on the annual accounts and consolidated accounts of banks and other financial institutions and 91/674/EEC on the annual accounts and consolidated accounts of insurance undertakings

Directive 2004/109/ EC of the European Parliament and of the Council of 15 December 2004 on the harmonization of transparency requirements in relation to information about issuers whose securities are admitted to trading on a regulated market and amending Directive 2001/34/EC

Directive 2003/6/EC of the European Parliament and of the Council of 28 January 2003 on insider dealing and market manipulation (market abuse) 
Directive 2006/43/EC of the European Parliament and of the Council of 17 May 2006 on statutory audits of annual accounts and consolidated accounts, amending Council Directives 78/660/EEC and 83/349/EEC and repealing Council Directive 84/253/EEC

Kuwait Capital Markets Act 2010

\section{Rules}

\section{UK}

Disclosure and Transparency Rules (DTR) (Financial Conduct Authority Handbook)

Principles for Businesses (PRIN) (Financial Conduct Authority Handbook)

Listing Principles (LP) (Financial Conduct Authority Handbook)

Listing Rules (LR) (Financial Conduct Authority Handbook)

\section{Kuwait}

Rule No. 2 of 2012 relating to disclosure

Rule No. 3 of 2011 relating to listing

\section{Case law}

David Massey v FSA 49(TCC) UKUT [2011] Upper Tribunal reference FIN/2009/0024 $R v$ Rigby and Bailey (2005) EWCA Crim 3487

\section{FSA decisions}

FSA/PN/056/2008 Woolworths Group plc FSA/PN/011/2009 Wolfson Microelectronics plc FSA/PN/015/2009 Entertainment Rights plc FSA/PN/102/2010 Photo Me International FSA/PN/036/2010 FSA/PN/015/2011 JJB Sports

FSA/PN/072/2011 Morrisons Supermarkets

FSA/PN/024/2013 Lamprell plc

FSA/PH/031/2013 Prudential Group

\section{Other}

Alshebli, A.R.A.S. (2015). Protecting Individual Investors under Kuwaiti Securities Law. PhD thesis, Leeds University.

Blair, M., B. Walker, G. \& Willey, S. (2012). Financial markets and exchanges law, (2 ${ }^{\text {nd }}$ edn.). Oxford: Oxford University Press.

Burke, J. (2009). Re-examining investor protection in Europe and the US. Murdoch University Electronic Journal of Law (16)2. http://elaw.murdoch.edu.au/index.php/elawmurdoch/article/viewFile/38/13.

McDonnell, B. (2012). A practitioner's guide to inside information, (2 $2^{\text {nd }}$ edn.). London: Sweet \& Maxwell.

Moloney, N. (2010). How to protect investors: Lessons from the EC and the UK. Cambridge: Cambridge University Press.

Wolfson, L. (2012). Continuing obligations: A practitioner's guide to the financial services authority listing regime $2012 / 2013$ (25 $5^{\text {th }}$ edn.). Stamford, CN: Thompson Reuters. 